\title{
EULAR evidence based recommendations for gout. Part II: Management. Report of a task force of the EULAR Standing Committee For International Clinical Studies Including Therapeutics (ESCISIT)
}

\author{
W Zhang, M Doherty, T Bardin, E Pascual, V Barskova, P Conaghan, J Gerster, \\ J Jacobs, B Leeb, F Lioté, G McCarthy, P Netter, G Nuki, F Perez-Ruiz, A Pignone, \\ J Pimentão, L Punzi, E Roddy, T Uhlig, I Zimmermann-Gòrska
}

See end of article for authors' affiliations

Correspondence to: Dr W Zhang, Academic Rheumatology, University of Nottingham, Clinical Sciences Building, City Hospital, Nottingham NG5 IPB, UK; weiya.zhang@ nottingham.ac.uk

Accepted 8 May 2006 Published Online First 30 May 2006
Objective: To develop evidence based recommendations for the management of gout. Methods: The multidisciplinary guideline development group comprised 19 rheumatologists and one evidence based medicine expert representing 13 European countries. Key propositions on management were generated using a Delphi consensus approach. Research evidence was searched systematically for each proposition. Where possible, effect size (ES), number needed to treat, relative risk, odds ratio, and incremental cost-effectiveness ratio were calculated. The quality of evidence was categorised according to the level of evidence. The strength of recommendation (SOR) was assessed using the EULAR visual analogue and ordinal scales.

Results: 12 key propositions were generated after three Delphi rounds. Propositions included both nonpharmacological and pharmacological treatments and addressed symptomatic control of acute gout, urate lowering therapy (ULT), and prophylaxis of acute attacks. The importance of patient education, modification of adverse lifestyle (weight loss if obese; reduced alcohol consumption; low animal purine diet) and treatment of associated comorbidity and risk factors were emphasised. Recommended drugs for acute attacks were oral non-steroidal anti-inflammatory drugs (NSAIDs), oral colchicine (ES $=0.87$ (95\% confidence interval, 0.25 to 1.50$)$ ), or joint aspiration and injection of corticosteroid. ULT is indicated in patients with recurrent acute attacks, arthropathy, tophi, or radiographic changes of gout. Allopurinol was confirmed as effective long term ULT (ES $=1.39$ (0.78 to 2.01)). If allopurinol toxicity occurs, options include other xanthine oxidase inhibitors, allopurinol desensitisation, or a uricosuric. The uricosuric benzbromarone is more effective than allopurinol $(E S=1.50(0.76$ to 2.24$))$ and can be used in patients with mild to moderate renal insufficiency but may be hepatotoxic. When gout is associated with the use of diuretics, the diuretic should be stopped if possible. For prophylaxis against acute attacks, either colchicine 0.5-1 mg daily or an NSAID (with gastroprotection if indicated) are recommended.

Conclusions: 12 key recommendations for management of gout were developed, using a combination of research based evidence and expert consensus. The evidence was evaluated and the SOR provided for each proposition.
D espite reasonable understanding of its pathogenesis and the availability of effective treatment, gout is often misdiagnosed or diagnosed late in its clinical course, and even when correctly diagnosed treatment is often suboptimal. For example, a recent cross sectional study showed that the prevalence of predefined mismanagement of gout (no drug treatment, analgesic alone, or urate lowering therapy without prophylaxis) was over two times greater with physician management than with patient self management. ${ }^{1}$ The risk was adjusted by age, sex, education, comorbidity, and number of attacks and was especially high in the first year of disease (relative risk $(R R)=3.8$, $\mathrm{p}<0.005) .{ }^{1}$ Other medication errors associated with gout appear to be widespread, especially with respect to colchicines. $^{2}$ Thus the European League Against Rheumatism (EULAR) gout task force was formed to develop evidence based recommendations on aspects relating both to the diagnosis and to the management of gout. This paper reports the second part of the project: evidence based recommendations for the management of gout.

\section{METHODS}

\section{Participants}

The same multidisciplinary guideline development group as for Diagnosis ${ }^{3}$ undertook the project. The objectives were, first, to agree key propositions related to the management of gout; second, to identify and critically appraise research evidence for the effectiveness and cost-effectiveness of the relevant treatments; and third, to generate recommendations based on a combination of the best available evidence and expert opinion.
Abbreviations: AHS, allopurinol hypersensitivity syndrome; ES, effect size; ESCISIT, EULAR Standing Committee for International Clinical Studies Including Therapeutics; EULAR, European League Against Rheumatism; ICER, incremental cost-effectiveness ratio; NNT, number needed to treat; NSAID, non-steroidal anti-inflammatory drug; QALY, quality of life years; RCT, randomised controlled trial; SOR, strength of recommendation; SUA, serum uric acid; VAS, visual analogue scale 
Table 1 Level of evidence

la Meta-analysis of randomised controlled trials

Ib Randomised controlled trial

lla Controlled study without randomisation

Ilb Quasi-experimental study

III Non-experimental descriptive studies, such as comparative, correlation, and case-control studies

IV Expert committee reports or opinion or clinical experience of respected authorities, or both

\section{Expert consensus}

Up to 10 propositions related to key clinical aspects in the management of gout were formulated, employing the identical Delphi technique and process as that used to develop propositions for Diagnosis. ${ }^{3}$ However, because the first 10 selected propositions did not address all treatment methods (specifically oral non-steroidal anti-inflammatory drugs (NSAIDs) for acute gout) it was agreed that the final number of propositions should be extended to include the next four propositions with the highest number of votes in the final Delphi round (round 3) and, as with the first 10 propositions, to permit amalgamation or rephrasing if required.

\section{Systematic search of published reports}

The same systematic search of reports published between January 1945 and January 2005 was undertaken for both diagnosis and management of gout (for details see part $\mathrm{I}^{3}$ and its appendix 1). Following the Delphi exercise, a proposition specific search, using the same search strategy as for Diagnosis, ${ }^{3}$ was undertaken.

\section{Inclusion/exclusion criteria}

Studies retrieved from the literature search were included only if they were concerned with clinical aspects of gout. Studies of hyperuricaemia were included only if they measured uric acid as an outcome for management of gout. The main focus of interest was on systematic reviews/metaanalyses, randomised controlled trials (RCTs)/controlled trials, uncontrolled trials (for example, one group intervention, quasi-experimental study, and so on), cohort studies, case-control studies, cross sectional studies, and economic evaluations. Case reports, review articles, editorials, and commentaries were excluded. Studies on healthy subjects or animals were also excluded.

\section{Level of evidence}

Evidence for efficacy was categorised according to the design characteristics of available studies using an established hierarchy $^{4}$ (table 1). Questions were answered using the best available evidence. For example, if a question on the effect of an intervention could be answered by level Ia evidence (that is, systematic review of RCTs) then studies of a weaker design (RCT, level Ib) were not reviewed. Results of the latest systematic review were used if there was more than one systematic review for the same question. However, questions on adverse effects were answered using both RCTs and observational studies irrespective of gout, as RCTs are not necessarily the best way to assess adverse effects, and gout may not be the target condition for which the side effects of a particular intervention are assessed. Questions of costeffectiveness were answered according to the outcome measure of effectiveness. For example, if the effectiveness was measured as "number of attacks prevented" or "quality of life years (QALYs) gained" only studies for gout were eligible. If the effectiveness was measured as "adverse events averted", any study for the proposed intervention was included.

Studies with direct evidence were considered first. If no direct evidence was available, studies with indirect evidence were examined. For example, evidence for weight loss in the management of gout was sought first but if none was available evidence for overweight/obesity as a risk factor for gout was examined.

\section{Outcome measures \\ Efficacy}

For treatment efficacy, effect size (ES) compared with placebo or active control as specified within the propositions was calculated for continuous outcomes such as the reduction of serum uric acid (SUA). ES is the standard mean difference-that is, the mean difference between a treatment and a control group divided by the standard deviation of the difference. It is therefore free of units and comparable across interventions. Clinically, an ES of 0.2 is considered small, 0.5 is moderate, and more than 0.8 is large. ${ }^{5}$ For dichotomous data, such as the percentage of patients with acute attacks or more than $50 \%$ pain relief, the number needed to treat (NNT) was estimated. ${ }^{6}$ The NNT is the estimated number of patients who need to be treated to either prevent an unwanted effect, such as an acute attack, or obtain a wanted outcome such as pain relief; therefore the smaller the NNT the better the treatment effect. The $95 \%$ confidence interval (CI) of the NNT was calculated using Altman's method. ${ }^{7}$ The dose-response relation between drug treatment and effects was analysed using a linearity test. Individual patient data were obtained from the original reports for this analysis and the results were pooled as appropriate. A multiple regression model was used to adjust co-variables such as concomitant treatment, age, sex, length of the disease, and duration of the treatment.

\section{Adverse effects}

For adverse effects, the relative risk (RR) was calculated from RCTs or cohort studies for the incident risk and from cross sectional studies for prevalent risk, whereas the odds ratio (OR) was calculated from case-control studies. ${ }^{8}$ Both present how many times more likely (or less likely) it is that a subject who is exposed to the drug or intervention will have adverse events than a subject who is not exposed. RR or $\mathrm{OR}=1$ indicates no increased risk, whereas $\mathrm{RR}$ or $\mathrm{OR}>1$ or $<1$ indicates an increased or decreased risk, respectively.

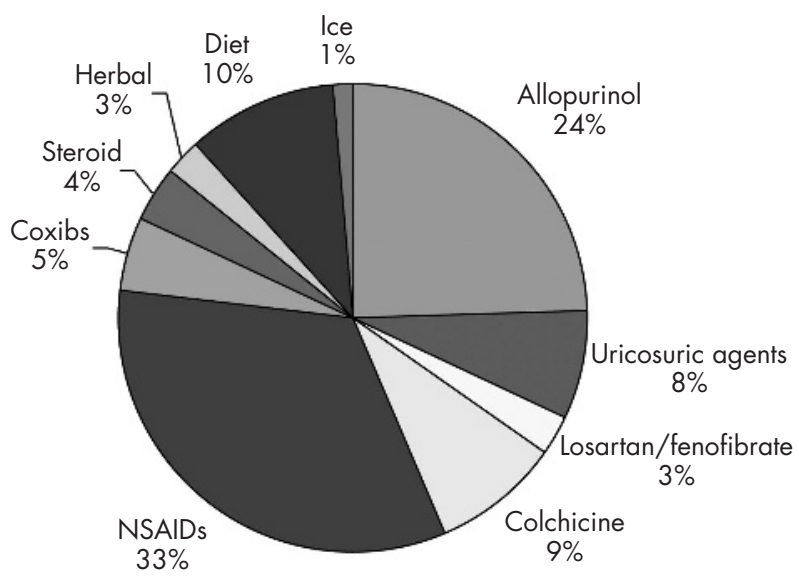

Figure 1 Treatment methods in the management of gout for which there is published research data. NSAID, non-steroidal anti-inflammatory drug. 


\section{Economic evaluation}

For economic evaluations, the incremental cost-effectiveness ratio (ICER) was calculated as the difference in cost between two treatments divided by their difference in effectiveness. When available, QALYs were used for the measurement of effectiveness; otherwise disease specific outcomes such as the reduction in SUA were used. In addition, study design, comparator, perspective, time horizon, discounting, total costs, and effectiveness were critically appraised.

The outcomes are presented with the point estimate (for example, the mean) and 95\% CI unless otherwise stated. Statistical pooling was undertaken as appropriate ${ }^{9}$ when there was more than one estimate for the same outcome using the same study design and a systematic review was not available.

\section{Ratification of propositions and strength of recommendation}

Following the literature search on each proposition and the initial drafting of the manuscript, the task force met to discuss each proposition. At this stage the wording (but not the content) of propositions could be adjusted to clarify specific statements and to reduce any ambiguity if the majority of the task force agreed. Two of the 14 propositions were amalgamated at this stage as they addressed the same intervention topic. The eventual 12 propositions were then ratified and a final adjusted manuscript was approved by all task force members. As for Diagnosis, ${ }^{3}$ the strength of each recommendation (SOR) was graded using the EULAR A-E ordinal scale $(\mathrm{A}=$ fully recommended, $\mathrm{B}=$ strongly recommended, $\mathrm{C}=$ moderately recommended, $\mathrm{D}=$ weakly recommended, and $\mathrm{E}=$ not recommended) and a $0-100 \mathrm{~mm}$ visual analogue scale (VAS), ${ }^{4}$ taking into account both the research evidence (efficacy, safety, and cost-effectiveness) and their clinical expertise (logistics, patient perceived acceptance, and tolerability). The mean VAS and $95 \%$ CI and the percentage of strongly to fully recommended $(\mathrm{A}-\mathrm{B})$ were calculated for each proposition.

\section{Future research agenda}

Up to 10 propositions for the future research agenda related to management of gout were formulated, employing the identical Delphi technique and process to that used to develop the future research agenda for Diagnosis. ${ }^{3}$

\section{RESULTS}

\section{General literature search}

The general search of published reports yielded 3316 hits (MEDLINE 1111, Old MEDLINE 6, EMBASE 820, CINAHL 17, Science Citation Index 1172, Cochrane 190). After deleting duplications, 2352 remained. Of these, only 181 studies met inclusion criteria, including 83 for diagnosis, ${ }^{3} 86$

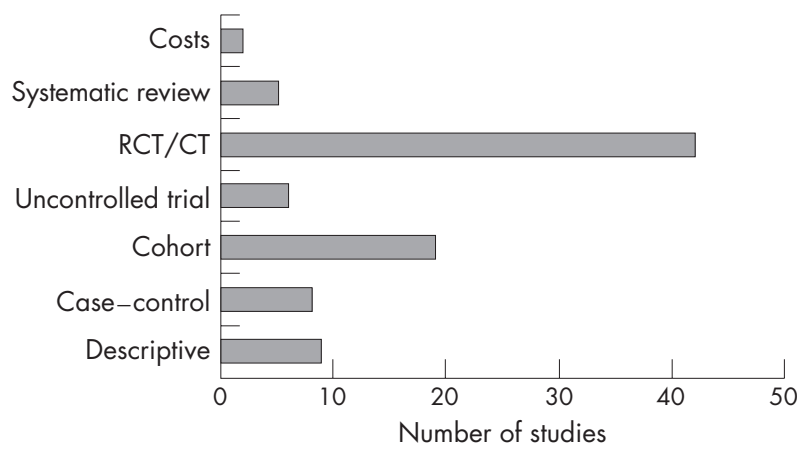

Figure 2 Types of evidence in the studies relating to the management of gout. CT, controlled trial; RCT, randomised controlled trial. for management, and 12 for both. Figure 1 shows the treatment modalities addressed in the 98 studies related to management; $86 \%$ of publications related to pharmacological treatments (for example, NSAIDs and coxibs, colchicine, steroids, allopurinol, febuxostat, uricosuric agents, losartan, fenofibrate); $3 \%$ to herbal remedies; and $11 \%$ to nonpharmacological treatment (for example, ice, diet). Although a broad range of treatments have been used to manage gout only those agreed using the Delphi consensus approach were assessed. Figure 2 shows the categories of evidence according to study designs for the 98 management related studies.

\section{Experts' opinion approach}

The experts were informed of the results of the general literature search and then the Delphi exercise was undertaken by email. The first round produced 146 propositions for management. After three anonymous Delphi rounds, 14 propositions were voted in; two of these were amalgamated as they related to the same topic, leaving 12 final propositions (table 2). The wording of eight of these (propositions numbers 1, 2, 3, 5, 7, 9, 11, and 12) were adjusted for clarification of key points at the final meeting.

\section{Assessment of propositions}

The proposition specific search was then undertaken and the results were merged with the results from the general search to form the basis of evidence for the evaluation of each proposition or methods within each proposition. The propositions are grouped by topic (general, management of acute attacks, urate lowering treatments, prophylaxis of acute attacks) with no weighting according to order.

1. Optimal treatment of gout requires both non-pharmacological and pharmacological modalities and should be tailored according to:

(a) specific risk factors (levels of serum urate, previous attacks, radiographic signs);

(b) clinical phase (acute/recurrent gout, intercritical gout, and chronic tophaceous gout);

(c) general risk factors lage, sex, obesity, alcohol consumption, urate elevating drugs, drug interactions and comorbidity).

\section{Strength of recommendation: 96 (95\% Cl, 93 to 98)}

It is apparent that the management strategy will vary according to the clinical presentation. Asymptomatic hyperuricaemia does not equate to gout and currently there is no evidence to support treatment of isolated hyperuricaemia with urate lowering therapy (ULT), though advice regarding lifestyle and treatment of associated comorbidity may be warranted. Acute gout is extremely painful so a key management objective will be rapid relief of symptoms. By contrast, assessment of a patient during an intercritical period or when chronic tophaceous gout is already present should lead to the development of an individualised long term management plan where the central objective is to reduce tissue levels of uric acid to dissolve existing crystals and to prevent further monosodium urate crystal formation (that is, a "cure").

The advice given to a patient and the selection and dose of drug treatment will vary according to several factors. For example, the severity of hyperuricaemia and clinical gout, the presence of comorbidity (for example, avoidance of uricosuric drugs in nephrolithiasis; dose adjustment of most drugs with renal impairment and old age), risk factors (weight reduction if obese, reduction in beer and alcohol if excessive), and the patient's age, sex, and other demographic features. One 
Table 2 Propositions and strength of recommendation: order based on topic (general, acute management, and chronic management)

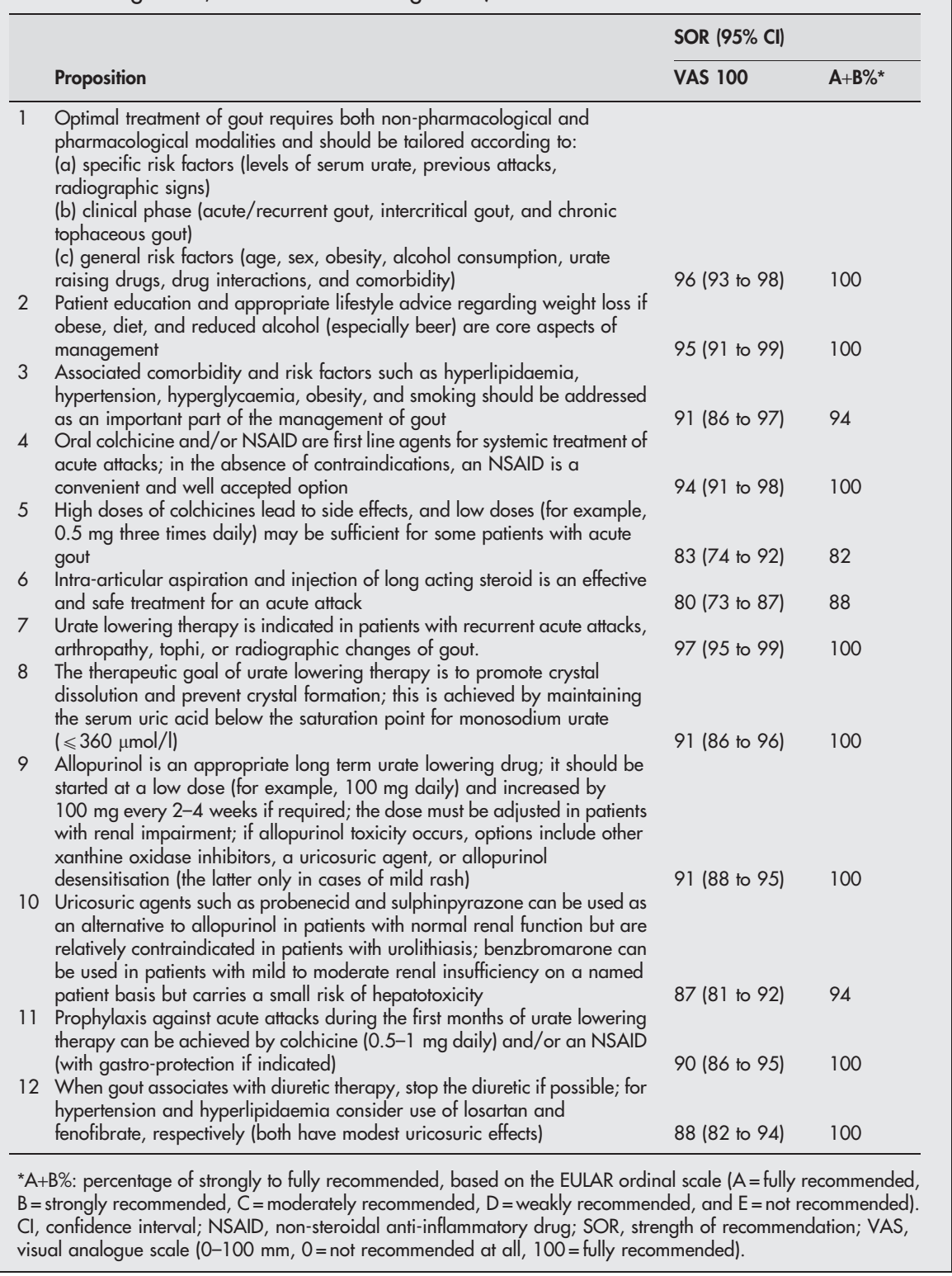

cohort study compared long term treatment effects ( 10 years) of urate lowering drugs between patients with chronic goutgrouped according to the presence or absence of tophi or radiographic damage to the affected joints or both-but found no significant difference between groups, as the treatment was effective for all types of patient. ${ }^{10}$ The dose requirement of allopurinol, used with prophylactic oral colchicine, has been shown to vary between patients in terms of achieving a target SUA level (uncontrolled trials) ${ }^{11} 12$ and the treatment response varies according to comorbidity such as hypertension and renal impairment (RCTs)..$^{13}$

For long term treatment of chronic gout, it has been well documented that either non-pharmacological treatments such as weight loss ${ }^{15}$ and low purine diet, ${ }^{16}$ or pharmacological treatments such as allopurinol ${ }^{11-13}$ are effective. The combination of pharmacological and non-pharmacological treatments (including patient information) appears rational. For example, given that both are effective (table 3), oral colchicine and topical ice packs may be combined to enhance the treatment effect for the relief of pain and other signs of inflammation, ${ }^{17}{ }^{18}$ although the two treatments have not yet been investigated in the same RCT using a factorial design. As non-pharmacological treatments are usually less harmful and less costly, they should always be considered either alone or in combination with pharmacological treatments, especially for long term management. With drug treatment, care must be taken to avoid increased toxicity through drug interaction, such as from colchicine with erythromycin (or ciclosporine). ${ }^{19} 20$

In conclusion, practitioners should always strive for optimal treatment. There is evidence that the combination of non-pharmacological and pharmacological treatments is more effective than individual monotherapy (level Ib). When managing gout it is important to take into account the clinical phase (level $\mathrm{Ib}$ ), the serum uric acid level and the frequency of previous attacks (level IIb), and associated comorbidity and risk factors (level Ib).

2. Patient education and appropriate lifestyle advice regarding weight loss if obese, diet, and reduced alcohol (especially beer) are core aspects of management. Strength of recommendation: 95 (95\% Cl, 91 to 99) 
Table 3 Evidence of efficacy: effect size and number needed to treat

\begin{tabular}{|c|c|c|c|c|c|}
\hline Comparison & Outcome & Level of evidence* & ES $(95 \% \mathrm{CI})$ & NNT $(95 \% \mathrm{Cl})$ & Reference \\
\hline $\begin{array}{l}\text { Acute management } \\
\text { Colchicine } v \text { placebo }\end{array}$ & $\begin{array}{l}\text { Pain VAS } \downarrow \\
\geqslant 50 \% \text { pain relief } \\
\text { Overall clinical improvement }\end{array}$ & Ib, 48 hours & $\begin{array}{l}0.87(0.25 \text { to } 1.50) \\
- \\
1.21(0.61 \text { to } 1.92)\end{array}$ & $\begin{array}{l}- \\
- \\
-\end{array}$ & 17 \\
\hline $\begin{array}{l}\text { Ice+colchicine + prednisone } v \\
\text { colchicine + prednisone }\end{array}$ & Pain VAS $\downarrow$ & lb, 7 days & $1.15(0.15$ to 2.12$)$ & - & 18 \\
\hline NSAIDs $v$ placebo & $\geqslant 50 \%$ pain relief & lb, 4 days & - & $3(1$ to 14$)$ & 21 \\
\hline $\begin{array}{l}\text { Prophylaxis and chronic managemer } \\
\text { Colchicine } v \text { placebo }\end{array}$ & $\geqslant 1$ attack prevented & $\mathrm{lb}, 3$ months & - & $2(1$ to 6$)$ & 22 \\
\hline Colchicine + probenecid $v$ probenecic & Attacks/patient/month & lb, 6 months & $0.74(0.08$ to 1.40$)$ & - & 23 \\
\hline Azapropazone $v$ allopurinol & $\begin{array}{l}\geqslant 1 \text { attack prevented } \\
\text { SUA } \downarrow\end{array}$ & Ila, 6 months & $\overline{0} .00(-0.26$ to 0.26$)$ & $\begin{array}{l}7(4 \text { to } 17) \\
-\end{array}$ & 24 \\
\hline Allopurinol + colchicine $v$ colchicine & $\begin{array}{l}\geqslant 1 \text { attack prevented } \\
\text { SUA } \downarrow\end{array}$ & $\mathrm{lb}, 1$ year & $\overline{1} .39(0.78$ to 2.01$)$ & $\begin{array}{l}9(-9 \text { to } 3) \\
-\end{array}$ & 25 \\
\hline $\begin{array}{l}\text { Benzbromarone } v \text { allopurinol in } \\
\text { patients with renal impairment }\end{array}$ & SUA $\downarrow$ & $\mathrm{lb}, 2$ years & $1.50(0.76$ to 2.24$)$ & $3(2$ to 15$)$ & 14 \\
\hline Fenofibrate $v$ placebo & $\begin{array}{l}\text { SUA } \downarrow \\
\text { Triglyceride } \downarrow\end{array}$ & lb, 6 weeks & $\begin{array}{l}1.13 \text { to }(0.18 \text { to } 2.07) \\
0.95(0.02 \text { to } 1.87)\end{array}$ & - & 26 \\
\hline
\end{tabular}

*See table 1 for definitions.

$\mathrm{Cl}$, confidence interval; ES, effect size; NNT, number needed to treat; NSAID, non-steroidal anti-inflammatory drug; SUA, serum uric acid; VAS, visual analogue scale; -, not available.

There is a strong belief that patient education and information access is an important determinant of outcome, especially in relation to successful lifestyle alteration and adherence to long term ULT. However, the benefits of education, either alone or as adjuvant therapy, have not been specifically studied in the management of gout.

Two cohort reports have shown that purine-rich food (meat and shellfish) and alcohol consumption (especially beer and spirits) are both associated with gout. ${ }^{27}{ }^{28}$ The RR was 1.51 (95\% CI, 1.17 to 1.95$)$ for seafood; 1.17 (1.11 to 1.22 ) for alcohol per $10 \mathrm{~g}$ increase; 1.49 ( 1.32 to 1.70$)$ for beer per serving per day; and 1.15 (1.04 to 1.28 ) for spirit per serving per day; dairy products were inversely associated with SUA. The risks were independent of other major risk factors such as age, sex, body mass index (BMI), diuretic use, hypertension, and renal failure. However, wine consumption did not increase SUA levels. ${ }^{27}{ }^{28}$ A small uncontrolled weight loss trial in 13 patients with gout showed that successful weight loss reduced SUA from $570 \mu \mathrm{mol} / \mathrm{l}$ (95\% CI, 520 to 620 ) at baseline to $470 \mu \mathrm{mol} / \mathrm{l}$ ( 420 to 520 ) after 16 weeks of treatment. ${ }^{15}$ The reduction in SUA occurred earlier (within four weeks) with a specific low purine diet in a larger uncontrolled trial of 305 hyperuricaemic patients. ${ }^{16}$ As weight loss was also observed in this trial, further studies are required to determine whether diet and weight loss have independent effects.

In conclusion, both low animal purine foods and weight loss reduce SUA in patients with gout (level IIb). Alcohol, particularly beer, is an independent risk factor for gout (level III). Therefore lifestyle advice that addresses obesity, dietary purine intake, and the amount and type of alcohol consumed should be considered in the management of gout. There is general agreement, but no research data, that education on gout and its treatment improves outcome either directly (for example, improved self efficacy) or indirectly through effects on adherence and lifestyle alteration (level IV).

3. Associated comorbidity and risk factors such as hyperlipidaemia, hypertension, hyperglycaemia, obesity and smoking should be addressed as an important part of the management of gout.

\section{Strength of recommendation: 91 (95\% Cl, 86 to 97)}

It is well established that raised SUA is associated with hyperlipidaemia, ${ }^{29-31}$ hypertension, ${ }^{32}{ }^{33}$ diabetes and insulin resistance, ${ }^{3435}$ and obesity ${ }^{15}{ }^{36}$ - conditions that are collectively termed the "metabolic syndrome". Therefore it would seem obvious good practice to consider these associated conditions when a patient presents with gout. Although there is no direct evidence to support smoking as a risk factor for gout, smoking strongly associates with alcohol consumption, ${ }^{37}$ which may in turn associate with gout. Importantly, however, smoking is a modifiable risk factor for cardiac and peripheral vascular disease, as well as many other diseases, and therefore needs to be addressed in a holistic approach to patient management.

Apart from the need to detect and treat these comorbidities in their own right, there is RCT evidence that some of the treatments for these co-morbidities and risk factors may also benefit gout. For example, losartan and fenofibrate both reduce SUA as well as reducing blood pressure and serum lipids, respectively. ${ }^{26}{ }^{38-43}$

In conclusion, recognition and treatment of co-morbidities and risk factors should be considered as a part of gout management and global patient care and may benefit both the comorbidity and gout (level Ib).

\section{Oral colchicine and/or NSAIDs are first line agents for systemic treatment of acute gout. In the absence of contraindications an NSAID is a convenient and well accepted option. \\ Strength of recommendation: 94 (95\% Cl, 91 to 98)}

One small (43 patients) and short term (48 hours) open RCT showed that oral colchicine is effective for acute gout. ${ }^{17}$ This placebo controlled trial examined colchicine at the loading dose of $1 \mathrm{mg}$ followed by $0.5 \mathrm{mg}$ every two hours until development of toxicity (nausea, vomiting, or diarrhoea). 
The ES was 0.87 (95\% CI, 0.25 to 1.50 ) for pain relief and 1.21 (0.61 to 1.92 ) for overall clinical improvement. The NNT for at least $50 \%$ pain relief was 3 (2 to 11 )-that is, one in three patients would experience that degree of pain relief should colchicine be used. However, all 22 patients in the treatment group had nausea, vomiting, or diarrhoea, whereas only five of 21 patients in the placebo group experienced these problems $(\mathrm{RR}=4.20(95 \% \mathrm{CI}, 1.95$ to 9.03$))$ (table 4$)$.

Intravenous (IV) colchicine has been used for treating acute gout. However, the potential for severe and even fatal toxicity from this route of administration causes great concern..$^{46} 47$

NSAIDs have a different mechanism of action but similar symptomatic effects to oral colchicine. One RCT has shown tenoxicam to be more effective than placebo for acute attacks. ${ }^{21}$ The NNT to obtain more than $50 \%$ pain relief was 3 (95\% CI, 1 to $14)$; that is, one in every three patients would achieve more than $50 \%$ relief of pain if tenoxicam were used. The results suggest equal efficacy to colchicine although direct comparison between these two agents has yet to be undertaken.

Many head to head comparisons have shown that different NSAIDs give similar benefits in acute gout, ${ }^{248-64}$ with no evidence for individual superiority in terms of clinical efficacy. However, a major concern with NSAIDs is their toxicity on the gastrointestinal tract. Meta-analyses have been undertaken both for evidence of gastrointestinal toxicity and for strategies to minimise gastrointestinal toxicity of NSAIDs, including co-administration of gastrointestinal protectors and alternative use of COX-2 selective inhibitors. ${ }^{4}$ For acute gout, the COX-2 selective inhibitors rofecoxib and etoricoxib have been investigated. ${ }^{65-67}$ However, the potential cardiovascular risk from selective and non-selective COX-2 inhibitors has recently been highlighted. ${ }^{68}{ }^{69}$ Whether they do more good than harm for gout-a condition which often coexists with cardiovascular disorders-remains unknown.

In conclusion, oral colchicine or NSAID are both effective at relieving symptoms of acute gout (level Ib). However, colchicine can cause severe diarrhoea, especially in high and frequent dosing, and NSAID use is associated with an increased risk of gastrointestinal bleeding and may have cardiovascular toxicity. Although oral NSAIDs are most commonly used, this preference is largely based on tradition and personal experience as the two treatments have not been directly compared.

5. High doses of colchicine lead to side effects, and low doses (for example $0.5 \mathrm{mg}$ three times daily) may be sufficient for some patients with acute gout.

Strength of recommendation: 83 (95\% Cl, 74 to 92)
Clinical trials have shown that colchicine at the standard recommended dose ( $1 \mathrm{~g}$ loading dose, followed by $0.5 \mathrm{mg}$ every two to three hours) is effective at relieving symptoms of acute gout. ${ }^{17}$ It is also effective, at the dose of $0.6 \mathrm{mg}$ three times a day, in preventing acute attacks in patients with chronic gout ${ }^{22}$ (table 3 ). However, both dosage regimens cause serious gastrointestinal side effects, especially diarrhoea (table 4). The possibility that a reduced dose or dosing frequency may allow retention of efficacy with a reduction in toxicity is widely debated. However, apart from case reports, ${ }^{70}$ there is no direct evidence to support a low dose regimen. Studies examining the benefits and risks from different doses of colchicine are still required.

In conclusion, oral colchicine at the high dose schedule is effective but also very toxic, even within a very short treatment period (level $\mathrm{Ib}$ ). There is popular support for an alternative lower dose regimen, as stated in the proposition, though rigorous evidence to support this new schedule is lacking (level IV).

\section{Intra-articular aspiration and injection of a long acting steroid is an effective and safe treatment for an acute attack. \\ Strength of recommendation: 80 (95\% Cl, 73 to 87$)$}

Although commonly used in practice, intra-articular aspiration (for immediate reduction of painful intra-articular hypertension as well as for diagnosis) and intra-articular injection of a long acting steroid have not been investigated in controlled trials. In one uncontrolled trial a single intraarticular injection of triamcinolone acetonide $10 \mathrm{mg}$ resulted in pain relief within 48 hours in all 19 patients with acute gout, $^{71}$ the mean VAS pain score $(0-100 \mathrm{~mm})$ reducing from 88 (range 82 to 93 ) at baseline to 0 (range 0 to 12) at end point. The treatment was well tolerated, no patients had side effects or rebound attacks, and none required additional treatment for the attack. Systemic administration (prednisone, triamcinolone, or ACTH) has also been used in patients in whom an NSAID or colchicine are contraindicated, with reportedly good results. ${ }^{72-76}$ In practice, this systemic approach is most commonly recommended for patients with severe oligoarticular or polyarticular attacks and for attacks in sites (for example, the midfoot) that are not readily amenable to aspiration. It is generally agreed that neither intra-articular nor systemic steroids should be used if coexistent septic arthritis is suspected.

In conclusion, intra-articular aspiration may be useful for an acute attack but there is no research evidence to support

Table 4 Evidence of safety: relative risk and $95 \%$ confidence intervals

\begin{tabular}{|c|c|c|c|c|}
\hline Comparison & Adverse events & $\mathrm{RR}^{*}(95 \% \mathrm{Cl})$ & Evidence & Reference \\
\hline \multirow[t]{2}{*}{ Colchicine $v$ placebo } & Nausea, vomiting or diarrhoea & 4.20 (1.95 to 9.03$)$ & $\mathrm{RCT}, 48$ hours & 17 \\
\hline & Diarrhoea & 8.38 (1.14 to 61.38$)$ & RCT, 3 months & 22 \\
\hline \multirow[t]{4}{*}{ Colchicine+probenecid $v$ probenecid } & Any & $1.69(0.95$ to 3.00$)$ & $\mathrm{RCT}, 6$ months & 23 \\
\hline & $\mathrm{Gl}$ & $1.69(0.95$ to 3.00$)$ & $\mathrm{RCT}, 6$ months & 23 \\
\hline & Diarrhoea & $1.35(0.60$ to 3.04$)$ & $\mathrm{RCT}, 6$ months & 23 \\
\hline & Nausea/vomiting & $1.98(0.85$ to 4.60$)$ & $\mathrm{RCT}, 6$ months & 23 \\
\hline \multirow[t]{4}{*}{ Azapropazone $v$ allopurinol } & Acute duodenal ulcer & $2.20(0.09$ to 53.59$)$ & $\mathrm{CT}, 6$ months & 24 \\
\hline & Nausea/dyspepsia & $51.68(3.21$ to 833.18$)$ & $\mathrm{CT}, 6$ months & 24 \\
\hline & Diarrhoea/abdominal pain & $2.20(0.23$ to 20.85$)$ & $\mathrm{CT}, 6$ months & 24 \\
\hline & Headache/dizziness & $1.10(0.19$ to 6.47$)$ & $\mathrm{CT}, 6$ months & 24 \\
\hline \multicolumn{5}{|l|}{ Allopurinol: } \\
\hline Allopurinol v placebo & Creatinine clearance & Reduced to $p>0.02$ & $\mathrm{RCT}, 2.5$ years & 13 \\
\hline Adjusted dose $v$ unadjusted dose & Rash, AHS, FPE, LCV & $1.96(0.34$ to 11.92$)$ & Cohort study, & 44 \\
\hline Exposure $v$ non-exposure & Cataract & $1.82(1.18$ to 2.80$)$ & Case-control & 45 \\
\hline
\end{tabular}

*RR: relative risk between treatment group and control group: $R R=1$, no difference; $R R>1$, more risk with treatment; $R R<1$, more risk with control. AHS, allopurinol hypersensitivity syndrome; $\mathrm{Cl}$, confidence interval; $\mathrm{CT}$, controlled trial; FPE, fixed pigmented drug eruption; $\mathrm{Gl}$, gastrointestinal; LCV, leucocytoclastic vasculitis; RCT, randomised controlled trial. 
its use (level IV). Intra-articular injection of a long acting steroid is effective at relieving the pain of an acute attack (level IIb). This may be especially useful for patients with a severe mono-articular attack and in those in whom an NSAID and colchicine are contraindicated.

7. Urate lowering therapy is indicated in patients with recurrent acute attacks, arthropathy, tophi, or radiographic changes of gout.

\section{Strength of recommendation: 97 (95\% Cl, 95 to 99)}

Given the unfavourable natural history of untreated gout, non-pharmacological urate lowering treatment (for example, advice on diet, lifestyle modification) should be initiated in every patient at presentation. However, there are sparse research data to guide the decision as to when to start urate lowering drug treatment. There is uniform agreement that urate lowering drugs should be recommended to patients with severe established gout-as indicated, for example, by tophi, gouty arthropathy, radiographic changes of gout, multiple joint involvement, or associated uric acid nephrolithiasis. There is less agreement, however, concerning initiation of urate lowering drug treatment in less severe gout-for example, following clinical presentation with the first acute attack. Opinion ranges from initiation of urate lowering drugs after even the first attack of gout (on the assumption that it is easier to treat and cure gout if there is a relatively small urate crystal load) through to waiting until further attacks occur and become sufficiently frequent to be troublesome (on the assumption that some patients will have relatively infrequent attacks that do not merit long term drug treatment with its associated inconvenience and risk of toxicity). As always, each clinical decision must be individualised according to specific patient characteristics (proposition 1), the balance of risk-benefit of long term drug treatment, and the wishes of the patient. It is agreed that informed patient opinion is central to such decision making (level IV).

8. The therapeutic goal of urate lowering therapy is to promote crystal dissolution and prevent crystal formation. This is achieved by maintaining the serum uric acid below the saturation point for monosodium urate $(\leqslant 360 \mu \mathrm{mol} / \mathrm{l}$ or $\leqslant 6 \mathrm{mg} / \mathrm{dl}$ ).

Strength of recommendation: 91 (95\% Cl, 86 to 96)

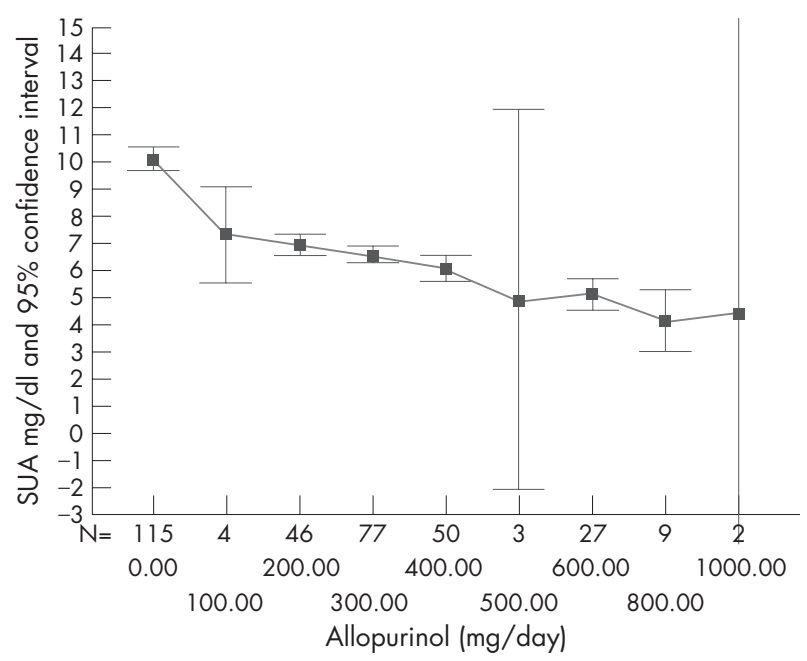

Figure 3 Dose dependent relation between allopurinol and serum uric acid (SUA). Pooled results from Yu ${ }^{12}$ and Rundles et $a^{\prime 1}(r=0.70, p<0.01)$.
Gout is a true crystal deposition disease which only occurs if urate crystals are present. If further urate crystal formation is halted in a patient and existing crystals are dissolved away, then that patient is essentially "cured". There are various strategies to reduce tissue urate levels below the saturation point where urate crystal formation can occur and to a low level that encourages crystal dissolution. Apart from urate saturation, the balance of inhibitory and promoting factors in joint tissues also influences urate crystal formation and dissolution; these factors may explain why only a minority of people who are supersaturated for monosodium urate ever form crystals. The level of SUA is presumed to be an indirect indication of joint tissue urate levels. The normal range of SUA is determined by sampling the local population and therefore varies from country to country and with time, depending on the prevalence of factors such as obesity that influence SUA; furthermore the normal range is lower in women, though less so after the menopause. In many populations an SUA that is in the "normal range" may still reflect levels in joint tissues that are above the saturation point for monosodium urate. Thus the target of urate lowering treatment is best centred on an SUA level that is linked to the saturation point of monosodium urate rather than to a normal laboratory range.

A level of SUA of $\leqslant 360 \mu \mathrm{mol} / \mathrm{l}$ reflects a tissue level that is likely to be well below this saturation point. One cohort study has shown that maintaining the SUA below $6.2 \mathrm{mg} / \mathrm{dl}$ $(370 \mu \mathrm{mol} / \mathrm{l})$ would significantly reduce tophi, whereas an SUA above $8.2 \mathrm{mg} / \mathrm{dl}(490 \mu \mathrm{mol} / \mathrm{l})$ did not reduce tophi. ${ }^{10}$ This was supported by other two cohort studies in which a linear relation was found between the level of SUA and reduction in tophi, ${ }^{77}$ and where depletion of urate crystals from knee synovial fluids could be achieved if the SUA was maintained below $6 \mathrm{mg} / \mathrm{dl} \quad(360 \mu \mathrm{mol} / \mathrm{l})$ for at least 12 months. $^{78}$ In some patients-for example, those with extensive tophi and a presumed very high crystal load-the therapeutic target may be to achieve SUA levels that are well below this minimum level to permit a faster "velocity" of tophi reduction. ${ }^{78}$ The specific SUA level that is made the therapeutic target may thus vary according to individual patient characteristics (proposition 1).

In summary, the aim of urate lowering therapy is "cure" through prevention of urate crystal formation and enhancement of crystal dissolution. To achieve this aim there are clinical data to support the requirement to maintain the SUA at or below a level of $360 \mu \mathrm{mol} / \mathrm{l}(6 \mathrm{mg} / \mathrm{dl})$ (level III). This SUA level reflects a tissue level that is below the saturation point for monosodium urate.

Table 5 Effect of reduction of serum uric acid upon treatment variables in patients with primary gout

\begin{tabular}{llll}
\hline Variable & $\boldsymbol{\beta}$ & $95 \% \mathrm{Cl}$ & $\mathrm{p}$ Value \\
\hline $\begin{array}{l}\text { Allopurinol } \\
\text { (100 mg increments) }\end{array}$ & -1.09 & -0.94 to -1.24 & 0.000 \\
$\begin{array}{l}\text { Sulphinpyrazone } \\
\text { (100 mg increments) }\end{array}$ & -0.09 & -0.01 to -0.18 & 0.034 \\
$\begin{array}{l}\text { Duration of treatment } \\
\text { (weeks) }\end{array}$ & -0.08 & -0.04 to -0.11 & 0.000 \\
$\begin{array}{l}\text { Age } \\
\text { (10 year increments) }\end{array}$ & -0.36 & -0.18 to -0.53 & 0.000 \\
\hline
\end{tabular}

Dependent variable: serum uric acid (SUA). Individual patient data were obtained from Yu's study (1965). ${ }^{12}$ Negative values mean a reduction in SUA (in $\mathrm{mg} / \mathrm{dll}$ ).

$\mathrm{Cl}$, confidence interval. 
9. Allopurinol is an appropriate long term urate lowering therapy. It should be started at a low dose (100 mg daily) and increased by $100 \mathrm{mg}$ every two to four weeks if required. The dose must be adjusted in patients with renal impairment. If allopurinol toxicity occurs, options include other xanthine oxidase inhibitors, a uricosuric agent, or allopurinol desensitisation (the latter only in cases of mild rash).

\section{Strength of recommendation: 91 (95\% Cl, 88 to 95)}

Although allopurinol has been used as an effective treatment for gout for decades, its clinical efficacy has not been examined in placebo controlled RCTs. One open RCT in 59 patients with chronic gout compared the combination of allopurinol $200 \mathrm{mg}$ daily plus colchicine $0.5 \mathrm{mg}$ twice a day $(\mathrm{n}=26)$ against colchicine $0.5 \mathrm{mg}$ twice a day alone $(\mathrm{n}=33)$. After two years a significantly greater reduction in SUA level was observed in those taking allopurinol plus colchicine $(\mathrm{ES}=1.39(95 \% \mathrm{CI}, 0.78$ to 2.01$))$. However, the number of patients experiencing acute attacks was similar in both groups during the first year $(\mathrm{NNT}=9(-9$ to 3$))$; serum creatinine concentrations were also similar in the two groups. ${ }^{25}$

One could question the requirement of a placebo control when a biochemical measure (SUA) is the primary outcome studied. Certainly a large number of uncontrolled trials have shown the urate lowering capability of allopurinol. A reanalysis based on individual patient data from two studies ${ }^{11} 12$ showed a significant dose-response relation between allopurinol and SUA (fig 3) in which every $100 \mathrm{mg}$ increment of allopurinol reduced SUA by approximately $1 \mathrm{mg} / \mathrm{dl}(60 \mu \mathrm{mol} /$ l) (table 5). There is general support for the "go low, go slow" strategy of starting allopurinol at $100 \mathrm{mg}$ daily and increasing by $100 \mathrm{mg}$ increments every few weeks until the therapeutic SUA target is achieved. Compared with giving only a fixed dose of $300 \mathrm{mg}$ (a very common practice throughout Europe), the possible benefits of slowly titrating up the dose include the following: reduced likelihood of provocation of acute attacks; reduced incidence of toxicity; tailoring of the dose to suit individual requirements; and emphasis on the importance of a sufficiently low target SUA. Nevertheless, although this strategy has some face validity and some potential advantages, formal comparison with a fixed dose strategy has not been undertaken.

Allopurinol may cause adverse events including the rare but potentially life threatening allopurinol hypersensitivity syndrome (AHS). This consists of an erythematous desquamating rash, fever, hepatitis, eosinophilia, and worsening renal function. ${ }^{79}$ One single blind, placebo controlled trial compared renal function (serum creatinine and creatinine clearance) in subjects with hyperuricaemia who received either allopurinol or placebo. ${ }^{13}$ After 2.5 years of treatment the trial overall found no significant increase of serum creatinine or decrease of creatinine clearance compared with placebo, but there was a reduction in creatinine clearance with allopurinol in hypertensive patients with glomerular filtration rates above $80 \mathrm{ml} / \mathrm{min}(\mathrm{p}<0.02)$. Unfortunately the trial did not report details of allopurinol dosage and the optimal doses of allopurinol in patients with varying renal function remains unknown, though the principle of using lower (especially starting) doses of allopurinol in patients with impaired renal function is generally accepted. One retrospective cohort study $(n=120)$ compared the risk of adverse drug reactions between patients whose allopurinol maintenance dose matched the recommended dose according to their creatinine clearance rate $(\mathrm{n}=52)$ and patients whose maintenance dose exceeded the recommended dose $(\mathrm{n}=68) .{ }^{44}$ The risk of rash, AHS, fixed pigmented drug eruption, or leucocytoclastic vasculitis was similar between the two groups $(\mathrm{RR}=1.96 \quad(95 \% \mathrm{CI}, 0.34$ to 11.92$))$.
Interestingly, one case-control study showed a higher risk of cataract extraction in elderly patients taking allopurinol $(\mathrm{OR}=1.82(1.18$ to 2.80$)){ }^{45}$

In an economic analysis allopurinol, selected as the prototype and most widely used urate lowering drug, was shown to be more effective $(72 \% \vee 5 \%$ acute attacks averted per year) and more costly than non-urate lowering drug treatment ( $\$ 426.27 \vee 267.27$ per patient per year).$^{80}$ ICER (cost per acute attack averted) was $\$ 247.40$ at base case scenario, and varied from $\$ 99.59$ to $\$ 489.26$ depending on patient characteristics and probability estimates. This suggested that for each patient taking allopurinol, it would cost society an additional $\$ 99.59$ to $\$ 489.26$ to prevent an additional acute attack of gouty arthritis compared with the strategy of not prescribing urate lowering drugs. Interestingly, the urate lowering drugs become cost saving (that is, more effective and less costly than non-urate lowering drug treatment) once a patient suffers three or more attacks a year.

If allopurinol toxicity does occur, alternative urate lowering treatments may be employed. As discussed in proposition 2, non-pharmacological approaches such as education, weight loss, reducing alcohol consumption, and dietary modification should always be considered. However, if urate lowering drugs are required, the current alternatives are other xanthine oxidase inhibitors or uricosuric agents. Several RCTs have shown that xanthine oxidase inhibitors other than allopurinol (for example, the metabolites of allopurinol, oxipurinol, tisopurine, and febuxostat) are effective in reducing SUA. ${ }^{81-88}$ However, their safety in patients who previously have developed AHP has not been established. Clinically, up to $40 \%$ of patients show cross reactivity between allopurinol and oxipurinol ${ }^{89}{ }^{90}$; the non-purine xanthine oxidase febuxostat is not reported to cause severe skin reactions and might be expected to have less cross reactivity than oxipurinol (though this has not been studied directly). Alternatively, as discussed in proposition 10, uricosuric agents may be considered. Allopurinol desensitisation may be successful but is only recommended if the above alternatives fail. It should not be attempted in patients with severe reactions or AHS. ${ }^{91-94}$

In conclusion, allopurinol is a cost-effective treatment for the long term management of chronic gout (level $\mathrm{Ib}$ ) and an effective urate lowering drug with a demonstrated doseresponse effect on SUA (level IIb). Although not formally studied, the strategy of giving a starting dose of $100 \mathrm{mg}$ daily (especially in those with renal impairment), with further $100 \mathrm{mg}$ increments until the target level of SUA is achieved, is favoured over a fixed dose strategy (level IV). For patients hypersensitive to allopurinol, other urate lowering treatments may be considered. Allopurinol desensitisation is a further option, but only in those with mild hypersensitivity to allopurinol (level IV).

10. Uricosuric agents such as probenecid and sulphinpyrazone can be used as an alternative to allopurinol in patients with normal renal function but are relatively contraindicated in patients with urolithiasis. Benzbromarone can be used in patients with mild to moderate renal insufficiency on a named patient basis but carries a small risk of hepatotoxicity.

\section{Strength of recommendation: 87 (95\% Cl, 81 to 92)}

One controlled trial compared the efficacy of probenecid 1$2 \mathrm{~g} /$ day or sulphinpyrazone $400 \mathrm{mg}$ /day to allopurinol 300 $600 \mathrm{mg} /$ day for up to two years of treatment ${ }^{95}$. Forty patients with uncomplicated chronic gout were allocated to either treatment according to the hospital record number (even or 
odd). The results showed that a similar number of patients experienced acute attacks $(11 / 20 \vee 9 / 17, p=0.90)$ but the mean reduction in SUA was greater with allopurinol $(4.6 \mathrm{mg} /$ $\mathrm{dl}$ or $270 \mu \mathrm{mol} / \mathrm{l})$ than with probenecid or sulphinpyrazone (3.3 mg/dl or $200 \mu \mathrm{mol} / \mathrm{l}$ ). However, detailed statistical data for SUA were not presented. Uncontrolled trials have investigated both agents, one of them showing smaller but statistically significant urate lowering effects of sulphinpyrazone $(0.09 \mathrm{mg} / \mathrm{dl}(95 \% \mathrm{CI}, 0.01$ to 0.18$))$ compared with allopurinol ( $1 \mathrm{mg} / \mathrm{dl}$ (95\% CI, 0.94 to 1.24$)$ ) per $100 \mathrm{mg}$ incremental dose (table 5). In another uncontrolled trial examined probenecid in patients with and without renal impairment; reduction in SUA was greater in those without renal impairment. ${ }^{96}$

Benzbromarone was compared with allopurinol in an open RCT of chronic gout patients with renal impairment. ${ }^{14}$ After two years of treatment the benzbromarone regimen (100$200 \mathrm{mg} /$ day using $50 \mathrm{mg}$ increments until the desired SUA level was achieved) showed a significantly greater reduction of SUA compared with the allopurinol regimen (100-200 mg/ day using 50-150 mg increments until the desired SUA level was achieved). The ES was 1.50 (95\% CI, 0.76 to 2.24) and more patients achieved the optimal SUA $(<6 \mathrm{mg} / \mathrm{dl}$ or $360 \mu \mathrm{mol} / \mathrm{l}$ ) with benzbromarone (NNT $=3$ (95\% CI, 2 to 15)). However, because of several case reports of hepatic failure or toxicity, ${ }^{97-101}$ the use of benzbromarone has become restricted in some European countries.

In conclusion, probenecid and sulphinpyrazone are both effective but probably inferior to allopurinol in lowering SUA (level IIa). They should not be used in patients with renal impairment (level IIb). In contrast, benzbromarone is a powerful uricosuric that is effective, even more so than allopurinol, in patients with renal impairment (level Ib). Its use, however, has been restricted because of rare cases of serious hepatic toxicity.

\section{Prophylaxis against acute attacks during the first months of urate lowering therapy can be achieved by colchicine $(0.5$ to $1 \mathrm{mg}$ daily) and/or an NSAID (with gastro-protection if indicated). \\ Strength of recommendation: 90 (95\% Cl, 86 to 95)}

Because acute gouty attacks may be induced by the rapid reduction in SUA that follows initiation or an increase in dose of urate lowering drugs, ${ }^{102}$ strategies have been devised to reduce or prevent such provocation of attacks during the first months of treatment. Two double blind RCTs have examined colchicine in this respect. ${ }^{22}{ }^{23}$ In one placebo controlled trial, 43 patients starting allopurinol for gout were randomly allocated to either colchicine $0.6 \mathrm{mg}$ twice daily $(\mathrm{n}=2 \mathrm{l})$ or placebo $(n=22)$. After three months, the percentage of patients with acute attacks was significantly less in the treatment group (7/21) than in the placebo group (17/22). The NNT was 2 (95\% CI, 1 to 6$)$, suggesting that colchicine would prevent one in two patients from experiencing an attack. However, colchicine also caused more diarrhoea than placebo $(\mathrm{RR}=8.38(95 \% \mathrm{CI}, 1.14$ to 61.38$)$ ). In a head to head comparison trial, 52 patients with intercritical gout were randomly allocated to probenecid $500 \mathrm{mg}$ three times daily plus colchicine $0.5 \mathrm{mg}$ daily or to probenecid $500 \mathrm{mg}$ three times daily plus placebo daily for six months. ${ }^{23}$ Both groups showed similar reduction in SUA $(\mathrm{ES}=-0.44(95 \%$ CI, -1.09 to 0.20$)$ ) but the group co-prescribed colchicine had fewer attacks per patient per month than the probenecidonly group $(\mathrm{ES}=0.74(0.08$ to 1.40$))$. Although both groups in this study had similar safety profiles (table 4), the possibility of toxicity, especially neurotoxicity, from long term colchicine treatment requires consideration.
Oral NSAIDs are also used for prophylaxis. Two published controlled trials compared azapropazone (an NSAID with uricosuric effects) $600 \mathrm{mg}$ twice daily with allopurinol, ${ }^{24} 49$ although one trial ${ }^{49}$ was part of the other multicentre study. ${ }^{24}$ Overall, 156 patients were treated for 24 weeks. ${ }^{24}$ While both treatments showed similar reductions in SUA $(\mathrm{ES}=0.00$ (95\% CI, -0.26 to 0.26$)$ ), azapropazone showed additional prophylactic benefit against acute attacks. The NNT was 7 (4 to 17) - that is, treating every seven patients with azapropazone would prevent one more patient from suffering an acute attack than would be the case if allopurinol was used. However, this was offset by a higher incidence of gastrointestinal upset in the azapropazone group (table 4). There are sparse data to guide the duration of prophylaxis; in general, longer prophylaxis is given for patients with greater crystal loads. The benefits of long term prevention must be balanced against toxicity.

In conclusion, evidence to support the use of low dose colchicine for prophylaxis against acute attacks when beginning urate lowering treatment is reasonable (level $\mathrm{Ib}$ ), whereas evidence for NSAIDs for the same purpose is less convincing (level IIa). Both agents have potentially serious side effects and their benefits and harms need to be carefully weighed.

\section{When gout associates with diuretic therapy, stop the diuretic if possible. For hypertension and hyperlipidaemia consider the use of losartan and fenofibrate, respectively (both have modest uricosuric effects). \\ Strength of recommendation: 88 (95\% Cl, 82 to 94)}

Diuretics, widely prescribed in the community, are a common risk factor for gout $(\mathrm{OR}=1.72(95 \% \mathrm{CI}, 1.67$ to 1.76)). ${ }^{103}$ Depending on its indication, it may be possible to stop chronic diuretic treatment in a patient who develops gout, or switch to an alternative drug regimen that does not contain a diuretic. For patients with gout and hypertension, an antihypertensive regimen that does not contain a thiazide should be considered. The angiotensin II receptor antagonist losartan is not only effective for hypertension but also has a uricosuric action ${ }^{40} 41$; ; it may therefore lower both blood pressure and SUA.

Apart from hypertension, hyperlipidaemia and other features of the metabolic syndrome are also associated with gout. A double blind, placebo controlled, crossover RCT of the lipid lowering agent fenofibrate has shown uricosuric and serum urate lowering effects. ${ }^{26}$ Ten patients with hyperlipidaemia were randomly assigned to one of three sequential treatments comprising fenofibrate $100 \mathrm{mg}$ three times daily, bezafibrate $200 \mathrm{mg}$ three times daily, or placebo, also three times daily. Each treatment lasted six weeks, with a three week washout in between. Fenofibrate showed significant reduction of SUA by $20 \%$ (95\% CI, $14 \%$ to $26 \%$ ) with an effect size of 1.13 ( 0.18 to 2.07 ). This reduction was accompanied by a $30 \%$ increase in renal uric acid clearance. However, there are no long term randomised controlled studies of losartan or fenofibrate as urate lowering agents for treating gout-either as monotherapy or in combination with other urate lowering drugs-so their clinical value in gout remains unclear.

In conclusion, diuretics should be stopped if possible in patients with gout (level IV) and, if appropriate, alternative antihypertensive treatment without diuretics should be considered (level IV). Uricosuric and urate lowering effects have been shown for the antihypertensive agent losartan (level IIb) and the lipid lowering agent fenofibrate (level Ib), making them attractive for use in gout patients requiring antihypertensive or lipid lowering treatment, respectively. However, the clinical role and cost-effectiveness of these drugs is still unknown. 


\begin{tabular}{|c|c|}
\hline No & Proposition \\
\hline 1 & $\begin{array}{l}\text { The optimal drug (colchicine or NSAID), dose, and duration for prophylaxis of acute attacks when starting } \\
\text { urate lowering treatment, and whether this should vary in different clinical settings (for example, in the } \\
\text { presence of tophi) needs to be determined }\end{array}$ \\
\hline 2 & $\begin{array}{l}\text { Studies are required to determine the optimal dose and frequency of oral colchicine for treatment of an } \\
\text { acute attack }\end{array}$ \\
\hline 3 & $\begin{array}{l}\text { Further studies are required to determine the target SUA for urate lowering treatment that ensures crystal } \\
\text { dissolution and eventual cure }\end{array}$ \\
\hline 4 & $\begin{array}{l}\text { Direct comparison (efficacy, side effects, cost utility) between allopurinol and alternative urate lowering } \\
\text { treatments are needed }\end{array}$ \\
\hline 5 & $\begin{array}{l}\text { The efficacy and safety of combined urate lowering treatment (for example, allopurinol plus a uricosuric } \\
\text { drug) should be determined and compared with monotherapy in patients with severe gout }\end{array}$ \\
\hline 6 & $\begin{array}{l}\text { The efficacy of educational programmes for lifestyle modification (weight loss, reduced alcohol intake, } \\
\text { restriction of dietary purines) in patients with gout needs to be assessed }\end{array}$ \\
\hline 7 & $\begin{array}{l}\text { The indications for initiating urate lowering treatment (for example, recurrent acute attacks, tophi, } \\
\text { polyarticular acute attacks, radiographic joint damage) need further evaluation }\end{array}$ \\
\hline 8 & $\begin{array}{l}\text { Whether initiation of urate lowering treatment during an acute attack is disadvantageous and should be } \\
\text { avoided, and if so for how long, requires investigation }\end{array}$ \\
\hline 9 & The possible benefits on cardiovascular disease of lowering SUA merit investigation \\
\hline
\end{tabular}

\section{Future research agenda}

Sixty one research topics were recommended initially. The nine that were agreed, after three Delphi rounds, as the most important topics for future research according to currently available research evidence and clinical practice are shown in table 6.

\section{DISCUSSION}

These are the first recommendations for the management of gout to be developed by EULAR. As with previous EULAR task forces for management of specific musculoskeletal disease, ${ }^{4}{ }^{104-106}$ we used an evidence based format that permits inclusion of both research evidence and expert opinion while maintaining a clear distinction between the two.

Various other practice guidelines for the management of gout have been published in recent years. ${ }^{107-110}$ However, the current EULAR recommendations have several differences and possible advantages over these guidelines, including first, an international panel of gout experts permitting broad representation of clinical practice within Europe; second, the inclusion of more recent research data; and third, the use of a rigorous evidence based format. The format that we used involved an anonymous Delphi consensus approach to derive key management propositions; a systematic search for research evidence to support each proposition; the pooling of data across populations where possible; and separate presentation of the category of evidence of supporting research data and the strength of recommendation for each proposition. Possible benefits of such an international evidence based approach include reduction in personal bias, good external validity and generalisability, and ready identification of areas of clinical practice where more research data are required. ${ }^{111}$ Several methodological issues merit emphasis.

First, we used the EULAR visual analogue and ordinal scale to grade the strength of recommendations. ${ }^{4}$ Unlike the traditional scale which only reflects the level of efficacy evidence, ${ }^{111} 112$ the EULAR scales allow a trade off between benefit versus harm, and research evidence versus clinical expertise, and the $95 \%$ confidence interval reflects the confidence of the group decision making (the wider the confidence interval the greater the variance within the group in supporting a proposition). This system has been used successfully in other evidence based recommendations $^{4} 104105113$ and is discussed further in the accompanying report on EULAR recommendations for the diagnosis of gout. $^{3}$
Second, again as discussed in the accompanying report on Diagnosis, ${ }^{3}$ the task force discussed at length the details relating to the Delphi exercise and the way in which propositions are developed. Particularly pertinent to the management propositions was the decision by the task force to opt for a free range of submitted propositions without specifying specific headings that each needed to be addressed by at least one proposition, and to accept only 10 final propositions, as in previous EULAR projects. ${ }^{4}{ }^{104-106}$ The task force realised that this approach would not necessarily result in exhaustive coverage of the topic and indeed, when the preliminary results were presented for feedback at the EULAR congress (Vienna, 2005) there was concern that the first 10 selected propositions did not address all treatment methods (specifically, there was omission of the use of oral NSAIDs for acute gout). Therefore it was agreed that the number of propositions should be extended to include the four with the next highest votes in the final Delphi round (round 3), which then resulted in inclusion of this topic. Nevertheless, these recommendations still only highlight certain aspects of management-they are not designed to be fully comprehensive or to cover every clinical situation related to gout. The task force recommend that for future projects, depending on the disease and the objectives, the possibility be considered of inviting propositions under prespecified headings if comprehensive coverage is desired. Also the more formal inclusion of feedback from EULAR members before finalisation of the recommendations should be considered as this clearly expanded and improved the current recommendations and resulted in a guideline set that more genuinely reflects the views of the EULAR membership. This feedback could be by oral and written communication following presentations at the EULAR Congress, or electronically following display of preliminary recommendations on the EULAR website.

Finally, as with the recommendations for diagnosis, the task force agreed to minor modifications, for the sake of clarity, to the wording of some propositions for management after they had been voted in, researched, and fully discussed, but no change was made to the key content of the propositions at this late stage.

There are various limitations to these recommendations. First, there are caveats relating to the research data. For example, as with any search strategy it is possible that some relevant research data were overlooked; most studies and clinical trials involve specialist referred gout patients who may be unrepresentative of the majority of the population 
with gout; and the quality of individual studies was not systematically assessed using established check lists such as the CONSORT statement for RCTs or the QUOROM statement for systematic reviews. ${ }^{114115}$ Second, although we examined the research evidence and combined this with expert opinion, the third important element of evidence based medicine, patient opinion, ${ }^{116}$ was omitted. For future task forces ESCISIT is currently considering appropriate ways in which patient opinion can be included. Third, the task force was comprised solely of rheumatologists. The omission of general practitioners, who manage a substantial proportion of gout patients in Europe, may have reduced the generalisability of the recommendations. It was interesting that even within the group of rheumatologists interested in gout there was considerable diversity of practice with respect to certain management issues, most notably when to initiate urate lowering drug treatment in a patient with confirmed gout; whether to use colchicine or NSAID prophylaxis when initiating urate lowering treatment, and what doses to use and for how long; the starting dose of allopurinol, the rate of dose escalation, and the maximum dose that may be used; and the willingness to use intra-articular corticosteroids for an acute attack. Therefore for relevant application of the recommendations we urge the user to study the commentary as well as the statements, to examine the confidence interval for each strength of recommendation (this reflects the diversity of opinion), and to examine the future research agenda which highlights where the group agreed it would be most helpful to have further research data to help guide clinical decisions.

\section{Conclusions}

We have developed the first EULAR recommendations for the management of gout based on both clinical practice and the best available evidence. Twelve key recommendations have been evaluated; these include non-pharmacological and pharmacological methods, management of the acute attack of gout, the use of long term urate lowering drug treatment, prophylaxis against acute attacks, and attention to comorbidity. A full review of this topic has also prompted nine key recommendations for the future research agenda. We trust that together with the accompanying propositions for diagnosis $^{3}$ these recommendations for management will lift the profile of this eminently treatable arthropathy and act as a catalyst for discussion between all health professionals involved in the diagnosis and management of patients with gout.

\section{ACKNOWLEDGEMENTS}

We would like to thank the European League Against Rheumatism for financial support, Helen Richardson for logistic support, Jane Robertson for literature search and database development, and Maggie Wheeler for language translations.

\section{Authors' affiliations}

M Doherty, E Roddy, W Zhang, Academic Rheumatology, University of Nottingham, Nottingham, UK

E Pascual, Sección de Rheumatologia, Hospital General Universitario de Alicante, Alicante, Spain

T Bardin, Fédération de Rhumatologie, Hôpital Lariboisière, Paris, France

V Barskova, Institute of Rheumatology RAMS, Moscow, Russian Federation

P Conaghan, Academic Unit of Musculoskeletal Disease, University of Leeds, Leeds, UK

J Gerster, Service de Rhumatologie, Hôpital Nestlé, CH 1011 LausanneCHUV, Switzerland

J Jacobs, Department of Rheumatology and Clinical Immunology, University Medical Centre Utrecht, Utrecht, Netherlands B Leeb, Second Department of Medicine, Lower Austrian Centre for Rheumatology, Stockerau, Austria
F Lioté, Fédération de Rhumatologie and INSERM U606, IFR 139, Hôpital Lariboisière, Paris, France

G McCarthy, Division of Rheumatology, Mater Misericordiae University Hospital, Dublin, Ireland

P Netter, U7R7561 CNR-UHP, Physiopathologie et Pharmacologie Articulaire, Universite Henri Poincare, Vandoeuvre Les Nancy, France G Nuki, Osteoarticular Research Group, University of Edinburgh,

Edinburgh, UK

F Perez-Ruiz, Sección de Rheumatologia, Hospital de Cruces,

Baracaldo, Spain

A Pignone, Departmento Medicina Interna, University of Florence, Florence, Italy

J Pimentão, Rheumatology Unit, Hospital Egas Moniz, Lisbon, Portugal L Punzi, Rheumatology Unit, University of Padova, Padova, Italy

T Uhlig, Department of Rheumatology, Diakonhjemmet Hospital, Oslo, Norway

I Zimmermann-Gòrska, Department of Rheumatology, Rehabilitation and Internal Medicine, Poznan University of Medical Sciences, Poznan, Poland

\section{REFERENCES}

1 Neogi T, Hunter DJ, Chasson CE, Cunningham JA, Zhang YQ. Frequency of inappropriate management of acute gout attacks. J Rheumatol 2006;33:104-9.

2 Mikuls TR, Curtis J, Allison J, Hicks RW, Saag KG. Medication errors with the use of gout related therapies: results from the United States Pharmacopeia MEDMARXsm Surveillance System. Arthritis Rheum 2004;50(9 suppl):S339-40.

3 Zhang W, Doherty M, Pascual-Gomez E, Bardin T, Barskova V, Conaghan P, et al. EULAR evidence based recommendations for gout. Part I: Diagnosis. Ann Rheum Dis 2006;65:1301-11.

4 Zhang W, Doherty M, Arden N, Bannwarth B, Bijlsma J, Gunther KP, et al. EULAR evidence based recommendations for the management of hip osteoarthritis: report of a task force of the EULAR Standing Committee for International Clinical Studies Including Therapeutics (ESCISIT). Ann Rheum Dis 2005;64:669-81.

5 Cohen J. Statistical power analysis for the behavioral sciences, 2nd edition. Hillsdale, NJ: Lawrence Erlbaum Associates, 1988.

6 Cook RJ, Sackett DL. The number needed to treat: a clinically useful measure of treatment effect. BMJ 1995;310:452-4.

7 Altman DG. Confidence intervals for the number needed to treat. BMJ 1998:317:1309-12.

8 Kleinbaum DG, Kuppler LL, Morgenstern H. Epidemiologic research principles and quantitative methods. New York: John Wiley and Sons, 1982.

9 Whitehead A, Whitehead J. A general parametric approach to the metaanalysis of randomized clinical trials. Stat Med 1991;10:1665-77.

10 McCarthy GM, Barthelemy CR, Veum JA, Wortmann RL. Influence of antihyperuricemic therapy on the clinical and radiographic progression of gout. Arthritis Rheum 1991;34:1489-94.

11 Rundles RW, Metz EN, Silberman HR. Allopurinol in the treatment of gout. Ann Intern Med 1966;64:229-58.

12 Yu TF. The effect of allopurinol in primary and secondary gout. Arthritis Rheum 1965;8:905-6.

13 Rosenfeld JB. Effect of long-term allopurinol administration on serial GFR in normotensive and hypertensive hyperuricemic subjects. Adv Exp Med Biol 1974;41:581-96.

14 Perez-Ruiz F, Calabozo M, Jose Fernandez-Lopez M, Herrero-Beites A, Ruiz-Lucea E, Garcia-Erauskin G, et al. Treatment of chronic gout in patients with renal function impairment: An open, randomized, actively controlled study. I Clin Rheumatol 1999;5:49-55.

15 Dessein PH, Shipton EA, Stanwix AE, Joffe BI, Ramokgadi J. Beneficial effects of weight loss associated with moderate calorie/carbohydrate restriction, and increased proportional intake of protein and unsaturated fat on serum urate and lipoprotein levels in gout: a pilot study. Ann Rheum Dis 2000;59:539-43.

16 Kullich W, Ulreich A, Klein G. Changes in uric acid and blood lipids in patients with asymptomatic hyperuricemia treated with diet therapy in a rehabilitation procedure [in German]. Rehabilitation 1989;28:134-7.

17 Ahern MJ, Reid C, Gordon TP, McCredie M, Brooks PM, Jones M. Does colchicine work? The results of the first controlled study in acute gout. Aust NZ J Med 1987; 17:301-4.

18 Schlesinger N, Detry MA, Holland BK, Baker DG, Beutler AM, Rull M, et al. Local ice therapy during bouts of acute gouty arthritis. I Rheumatol 2002;29:331-4.

19 Caraco Y, Putterman C, Rahamimov R, Ben Chetrit E. Acute colchicine intoxication - possible role of erythromycin administration. J Rheumatol 1992;19:494-6.

20 Minetti EE, Minetti L. Multiple organ failure in a kidney transplant patient receiving both colchicine and cyclosporine. J Nephrol 2003:16:421-5.

21 Garcia de la Torre, I. A comparative, double-blind, parallel study with tenoxicam vs placebo in acute gouty arthritis [in Spanish]. Investigacion Medica Internacional 1987;14:92-7.

22 Borstad GC, Bryant LR, Abel MP, Scroggie DA, Harris MD, Alloway JA. Colchicine for prophylaxis of acute flares when initiating allopurinol for chronic gouty arthritis. J Rheumatol 2004;31:2429-32. 
23 Paulus HE, Schlosstein LH, Godfrey RG, Klinenberg JR, Bluestone R. Prophylactic colchicine therapy of intercritical gout. A placebo-controlled study of probenecid-treated patients. Arthritis Rheum 1974;17:609-14.

24 Templeton JS. Azapropazone or allopurinol in the treatment of chronic gout and/or hyperuricaemia. A preliminary report. Br J Clin Pract 1982;36:353-8.

25 Gibson T, Simmonds HA, Potter C, Rogers V. A controlled study of the effect of long term allopurinol treatment on renal function in gout. Adv Exp Med Biol 1980; 122A:257-62

26 Bastow MD, Durrington PN, Ishola M. Hypertriglyceridemia and hyperuricemia: effects of two fibric acid derivatives (bezafibrate and fenofibrate) in a double-blind, placebo-controlled trial. Metab Clin Exp 1988;37:217-20.

27 Choi HK, Atkinson K, Karlson EW, Willett W, Curhan G. Alcohol intake and risk of incident gout in men: a prospective study. Lancet 2004;363:1277-81.

28 Choi HK, Atkinson K, Karlson EW, Willett W, Curhan G. Purine-rich foods, daily and protein intake, and the risk of gout in men. N Engl J Med 2004;350:1093-103.

29 Frank 0 . Observations concerning the incidence of disturbance of lipid and carbohydrate metabolism in gout. Adv Exp Med Biol 1974;41:495-8.

30 Jacobelli S, Arteaga A, Bidegain F. Cholesterol distribution among lipoprotein fractions in patients with gout and normal controls. J Rheumatol 1986; 13:774-7

31 Takahashi S, Yamamoto T, Moriwaki Y, Tsutsumi Z, Higashino K. Increased concentrations of serum Lp(a) lipoprotein in patients with primary gout. Ann Rheum Dis 1995;54:90-3.

32 Lin K-C, Tsao H-M, Chen C-H, Chou P. Hypertension was the major risk factor leading to development of cardiovascular diseases among men with hyperuricemia. J Rheumatol 2004;31:1152-8.

33 Rapado A. Relationship between gout and arterial hypertension. Adv Exp Med Biol 1974;41:451-9.

34 Grodzicki T, Palmer A, Bulpitt CJ. Incidence of diabetes and gout in hypertensive patients during 8 years of follow-up. J Hum Hypertens 1997; 11:583-5.

35 Tuomilehto J, Zimmet P, Wolf E, Taylor R, Ram P, King H. Plasma uric acid level and its association with diabetes mellitus and some biologic parameters in a biracial population of Fiii. Am J Epidemiol 1988;127:321-36.

36 Lyu LC, Hsu CY, Yeh CY, Lee MS, Huang SH, Chen CL. A case-control study of the association of diet and obesity with gout in Taiwan. Am J Clin Nutr 2003;78:690-701

37 Wetzels JJL, Kremers SPJ, Vitoria PD, De Vries H. The alcohol-tobacco relationship: a prospective study among adolescents in six European countries. Addiction 2003;98:1755-63.

38 Feher MD, Hepburn AL, Hogarth MB, Ball SG, Kaye SA. Fenofibrate enhances urate reduction in men treated with allopurinol for hyperuricaemia and gout. Rheumatology 2003;42:321-5.

39 Liberopoulos E, Christides D, Elisaf M. Comparative effects of losartan and irbesartan on serum uric acid in hypertensive patients with hyperuricemia and gout. J Hypertens 2002;20:347.

40 Puig JG, Mateos F, Buno A, Ortega R, Rodriguez F, Dal Re R. Effect of eprosartan and losartan on uric acid metabolism in patients with essential hypertension. J Hypertens 1999;17:1033-9.

41 Takahashi S, Moriwaki Y, Tsutsumi Z, Yamamoto T, Hada T. Effect of a combination therapy with losartan and anti-hyperuricemic agents on uric acid metabolism in gout patients with hypertension. J Rheumatol 2001;28:M37.

42 Takahashi S, Moriwaki Y, Yamamoto T, Tsutsumi Z, Ka T, Fukuchi M. Effects of combination treatment using anti-hyperuricaemic agents with fenofibrate and/or losartan on uric acid metabolism. Ann Rheum Dis 2003:62:572-5.

43 Wurzner G, Gerster JC, Chiolero A, Maillard M, Fallab-Stubi CL, Brunner HR, et al. Comparative effects of losartan and irbesartan on serum uric acid in hypertensive patients with hyperuricaemia and gout. $J$ Hypertens 2001; 19:1855-60

44 Vazquez-Mellado J, Morales EM, Pacheco-Tena C, Burgos-Vargas R. Relation between adverse events associated with allopurinol and renal function in patients with gout. Ann Rheum Dis 2001;60:981-3.

45 Garbe E, Suissa S, LeLorier J. Exposure to allopurinol and the risk of cataract extraction in elderly patients. Arch Ophthalmol 1998;116:1652-6.

46 Bonnel RA, Villalba ML, Karwoski CB, Beitz J. Deaths associated with inappropriate intravenous colchicine administration. J Emerg Med 2002;22:385-7.

47 Evans TI, Wheeler MT, Small RE, Breitbach SA, Sanders KM, Roberts WN. A comprehensive investigation of inpatient intravenous colchicine use shows more education is needed. J Rheumatol 1996;23:143-8

48 Altman RD, Honig S, Levin JM, Lightfoot RW. Ketoprofen versus indomethacin in patients with acute gouty arthritis: a multicenter, double blind comparative study. J Rheumatol 1988;15:1422-6.

49 Daymond TJ, Laws D, Templeton JS. A comparison of azapropazone and allopurinol in the treatment of chronic gout. Br J Clin Pharmacol 1983; 15:157.

50 Douglas $\mathbf{G}$, Thompson M. A comparison of phenylbutazone and flufenamic acid in the treatment of acute gout. Ann Phys Med 1970;10:275-80.

51 Eberl R, Dunky A. Meclofenamate sodium in the treatment of acute gout. Results of a double-blind study. Arzneimittel-Forschung 1983:33:641-3.

52 Fraser RC, Davis RH, Walker FS. Comparative trial of azapropazone and indomethacin plus allopurinol in acute gout and hyperuricaemia. J R Coll Gen Pract 1987;37:409-11.

53 Klumb EM, Pinheiro GRC, Ferrari A, Albuquerque EMN. The treatment of acute gout arthritis. Double-blind randomized comparative study between nimesulid and indomethacin. Rev Brasil Med 1996;53:540-6.
54 Lederman R. A double-blind comparison of Etodolac (Lodine (R)) and high doses of naproxen in the treatment of acute gout. Adv Ther 1990;7:344-54.

55 Lomen PL, Turner LF, Lamborn KR, Winblad MA, Sack RL, Brinn EL. Flurbiprofen in the treatment of acute gout. A comparison with indomethacin. Am J Med 1986;80:134-9.

56 Maccagno A, Di Giorgio E, Romanowicz A. Effectiveness of etodolac ("Lodine") compared with naproxen in patients with acute gout. Curr Med Res Opin 1991:12:423-9.

57 Reardon JA, Stockman A, Darlington LG, Scott JT. Double-blind trial of feprazone and phenylbutazone in acute gout. Curr Med Res Opin 1980;6:445-8.

58 Ruotsi A, Vainio U. Treatment of acute gouty arthritis with proquazone and indomethacin. A comparative, double-blind trial. Scand J Rheumatol Suppl 1978;21:15-17.

59 Shrestha M, Morgan DL, Moreden JM, Singh R, Nelson M, Hayes JE. Randomized double-blind comparison of the analgesic efficacy of intramuscular ketorolac and oral indomethacin in the treatment of acute gouty arthritis. Ann Emerg Med 1995;26:682-6.

60 Siegmeth W, Placheta P. Double-blind trial: ketoprofen versus phenylbutazone in acute gouty arthritis (author's translation) [in German] Wiener Klinische Wochenschrift 1976;88:535-7.

61 Sturge RA, Scott JT, Hamilton EB, Liyanage SP, Dixon ST, Engler C. Multicentre trial of naproxen and phenylbutazone in acute gout. Adv Exp Med Biol 1977;76B:290-6.

62 Tumrasvin T, Deesomchok U. Piroxicam in treatment of acute gout high dose versus low dose. J Med Assoc Thailand 1985:68:111-16.

63 Tweddell ED, Willcocks WA. An evaluation of piroxicam, a new non-steroidal anti-inflammatory agent. A multicentre trial. S Afr Med J 1981;59:915-16.

64 Weiner GI, White SR, Weitzner RI, Rubinstein HM. Double-blind study of fenoprofen versus phenylbutazone in acute gouty arthritis. Arthritis Rheum 1979;22:425-6.

65 Cheng TT, Lai HM, Chiu CK, Chem YC. A single-blind, randomized, controlled trial to assess the efficacy and tolerability of rofecoxib, diclofenac sodium, and meloxicam in patients with acute gouty arthritis. Clin Ther 2004; $26: 399-406$.

66 Rubin BR, Burton R, Navarra S, Antigua J, Londono J, Pryhuber KG, et al. Efficacy and safety profile of treatment with etoricoxib $120 \mathrm{mg}$ once daily compared with indomethacin $50 \mathrm{mg}$ three times daily in acute gout: a randomized controlled trial. Arthritis Rheum 2004;50:598-606.

67 Schumacher HR, Boice JA, Daikh DI, Mukhopadhyay S, Malmstrom K, Ng J, et al. Randomised double blind trial of etoricoxib and indomethacin in treatment of acute gouty arthritis. BMJ 2002;324:1488-92.

68 Solomon SD, McMurray JJV, Pfeffer MA, Wittes J, Fowler R, Finn P, et al. Cardiovascular risk associated with celecoxib in a clinical trial for colorectal adenoma prevention. N Engl J Med 2005;352:1071-80.

69 Bresalier RS, Sandler RS, Quan H, Bolognese JA, Oxenius B, Horgan K, et al. Cardiovascular events associated with rofecoxib in a colorectal adenoma chemoprevention trial. N Engl J Med 2005;352:1092-102.

70 Morris I, Varughese G, Mattingly P. Lesson of the week - colchicine in acute gout. BMJ 2003;327:1275-6.

71 Fernandez C, Noguera R, Gonzalez JA, Pascual E. Treatment of acute attacks of gout with a small dose of intraarticular triamcinolone acetonide. J Rheumatol 1999:26:2285-6.

72 Alloway JA, Moriarty MJ, Hoogland YT, Nashel DJ. Comparison of triamcinolone acetonide with indomethacin in the treatment of acute gouty arthritis. J Rheumatol 1920;20:111-13.

73 Groff GD, Franck WA, Raddatz DA. Systemic steroid therapy for acute gout a clinical trial and review of the literature [review] [40 refs]. Semin Arthritis Rheum 1990;19:329-36.

74 Siegel LB, Alloway JA, Nashel DJ. Comparison of adrenocorticotropic hormone and triamcinolone acetonide in the treatment of acute gouty arthritis. J Rheumatol 1994:21:1325-7.

75 Taylor CT, Brooks NC, Kelley KW. Corticotropin for acute management of gout. Ann Pharmacother 2001;35:365-8.

76 Werlen D, Gabay C, Vischer TL. Corticosteroid therapy for the treatment of acute attacks of crystal-induced arthritis: an effective alternative to nonsteroidal antiinflammatory drugs [see comment]. Rev Rhum (English edition) 1996;63:248-54.

77 Perez-Ruiz F, Calabozo M, Pijoan Jl, Herrero-Beites AM, Ruibal A. Effect of urate-lowering therapy on the velocity of size reduction of tophi in chronic gout. Arthritis Rheum 2002:47:355-60.

78 Li-Yu J, Clayburne G, Sieck M, Beutler AM, Rull M, Eisner E, et al. Treatment of chronic gout. can we determine when urate stores are depleted enough to prevent attacks of gout? J Rheumatol $2001 ; 28: 577-80$

79 Hande KR, Noone RM, Stone WJ. Severe allopurinol toxicity. Description and guidelines for prevention in patients with renal insufficiency. Am J Med 1984;76:47-56

80 Ferraz MB, O'Brien B. A cost effectiveness analysis of urate lowering drugs in nontophaceous recurrent gouty arthritis. J Rheumatol 1995;22:908-14.

81 Becker MA, Kisicki J, Khosravan R, Wu J, Mulford D, Hunt B, et al. Febuxostat (TMX-67), a novel, non-purine, selective inhibitor of xanthine oxidase, is safe and decreases serum urate in healthy volunteers. Nucleosides Nucleotides Nucleic Acids 2004;23:1111-16.

82 Becker MA, Schumacher H, Wortmann RL, Joseph-Ridge N, Lademacher C. A safety and efficacy clinical trial of a novel nun-purine selective inhibitor of xanthine oxidase, febuxostat in subjects with gout. Ann Rheum Dis 2004;63:60

83 Becker MA, Schumacher HR, Wortmann RL, MacDonald PA, Palo WA, Eustace $D$, et al. Febuxostat, a novel nonpurine selective inhibitor of xanthine oxidase: a twenty-eight-day, multicenter, phase II, randomized, doubleblind, placebo-controlled, dose-response clinical trial examining safety and efficacy in patients with gout. Arthritis Rheum 2005;52:916-23. 
84 Joseph-Ridge N. Phase II, dose-response, safety and efficacy clinical trial of a new oral xanthine oxidase inhibitor TMX-67 (febuxostat) in subjects with gout. Arthritis Rheum 2002;46:S142.

85 Kamatani N, Fujimori S, Hada T, Hosoya T, Kato R, Matsuzawa $Y$, et al. Phase II dose-response clinical trial using febuxostat (TMX-67), a novel-type xanthine oxidase/xanthine dehydrogenase inhibitor, for gout and hyperuricemia. Arthritis Rheum 2003;48:S530.

86 Kamatani N, Fujimori S, Hada T, Hosoya T, Matsuzawa Y, Ueda T, et al. Febuxostat, a novel non-purine selective inhibitor of xanthine oxidase, in an allopurinol-controlled phase III clinical trial in Japanese subjects with gout or hyperuricemia. Arthritis Rheum 2004;50:S336-7.

87 Kamatani N, Fujimori S, Hada T, Hosoya T, Matsuzawa Y, Ueda J, et al. Febuxostat, a novel non-purine selective inhibitor of xanthine oxidase, in a phase III placebo-controlled double-blind clinical trial in Japanese subjects with gout or hyperuricemia. Arthritis Rheum 2004;50:S337.

88 WalterSack I, deVries JX, Ernst B, Frei M, Kolb S, Kosmowski J, et al. Uric acid lowering effect of oxipurinol sodium in hyperuricemic patients therapeutic equivalence to allopurinol. J Rheumatol 1996;23:498-501 .

89 Lockard O, Harmon C, Nolph K, Irvin W. Allergic reaction to allopurinol with cross-reactivity to oxypurinol. Ann Intern Med 1976;85:333-5.

90 O'Duffy J. Oxypurinol therapy in allopurinol-sensitive patients [abstract]. Arthritis Rheum 1993:36(suppl 9):S159.

91 Fam AG, Lewtas J, Stein J, Paton TW. Desensitization to allopurinol in patients with gout and cutaneous reactions. Am J Med 1992;93:299-302.

92 Fam AG, Dunne SM, lazzetta J, Paton TW. Efficacy and safety of desensitization to allopurinol following cutaneous reactions. Arthritis Rheum 2001:44:231-8.

93 Monev SD. How should hyperuricemia be treated in a patient with allopurinol hypersensitivity? Cleveland Clin J Med 2001;68:597-8

94 Walz-LeBlanc BAE, Reynolds WJ, MacFadden DK. Allopurinol sensitivity in a patient with chronic tophaceous gout: success of intravenous desensitization after failure of oral desensitization. Arthritis Rheum 1991:34:1329-31.

95 Scott JT. Comparison of allopurinol and probenecid. Ann Rheum Dis 1966;25:623-6.

96 Bartels EC, Matossian GS. Gout: six-year follow-up on probenecid (benemid) therapy. Arthritis Rheum 1959:2:193-202.

97 Jansen TLT, Reinders MK, Van Roon EN, Brouwers JRBJ. Benzbromarone withdrawn from the European market: another case of "absence of evidence is evidence of absence" ? Clin Exp Rheumatol 2004;22:651.

98 Marukawa Y, Oishi N, Mizukoshi E, Tsuji H, Yamashita T, Kaji K, et al. A case of subacute hepatic failure associated with benzbromarone [in Japanese]. Acta Hepatol Jpn 2004;24:354-9.

99 Arai M, Yokosuka O, Fujiwara K, Kojima H, Kanda T, Hirasawa H, et al. Fulminant hepatic failure associated with benzbromarone treatment: a case report. J Gastroenterol Hepatol 2002;17:625-6.

100 Wagayama H, Shiraki K, Sugimoto K, Fujikawa K, Shimizu A, Takase K, et al. Fatal fulminant hepatic failure associated with benzbromarone. $J$ Hepatol 2000;32:874.
101 Van Der Klauw MM, Houtman PM, Stricker BHC, Spoelstra P. Hepatic injury caused by benzbromarone. J Hepatol 1994;20:376-9.

102 Yamanaka H, Togashi R, Hakoda M, Terai C, Kashiwazaki S, Dan T, et al. Optimal range of serum urate concentrations to minimize risk of gouty attacks during anti-hyperuricemic treatment. Adv Exp Med Biol 1998;431:13-18.

103 Mikuls TR, Farrar JT, Bilker WB, Fernandes S, Schumacher HR, Saag KG Gout epidemiology: results from the UK General Practice Research Database, 1990-1999. Ann Rheum Dis 2005:64:267-72.

104 Jordan KM, Arden NK, Doherty M, Bannwarth B, Bijlsma JW, Dieppe P, et al. EULAR Recommendations 2003: an evidence based approach to the management of knee osteoarthritis. Report of a Task Force of the Standing Committee for International Clinical Studies Including Therapeutic Trials (ESCISIT). Ann Rheum Dis 2003:62:1145-55.

105 Pendleton A, Arden N, Dougados M, Doherty M, Bannwarth B, Bijlsma JW, et al. EULAR recommendations for the management of knee osteoarthritis: report of a task force of the Standing Committee for International Clinical Studies Including Therapeutic Trials (ESCISIT). Ann Rheum Dis 2000;59:936-44.

106 Zochling J, van der Heijde D, Burgos-Vargas R, Collantes E, Davis J, Dijkmans $B$, et al. ASAS/EULAR recommendations for the management of ankylosing spondylitis. Ann Rheum Dis 2006:65:442-52

107 Prodigy Guidance - Gout. http:www prodigy nhs uk/guideline asp? gt= Gout 2004; accessed 09-05-, 2005

108 Meyers OL, Cassim B, Mady GM. Hyperuricaemia and gout: clinical guidelines. S Afr Med J 2003:93:961-71.

109 Nakajima H, Matsuzawa Y. Introduction of the new guideline for the management of hyperuricemia and gout with special reference to its policy. Jpn J Clin Med 2003;61(suppl 1):442-9.

110 Roemjinders H, Gorter KJ. Dutch general practitioners gout guidelines. Ned Tiid Genees 2002; 146:309-13.

111 Shekelle PG, Woolf SH, Eccles M, Grimshaw J. Clinical guidelines: developing guidelines [review]. BMJ 1999;318:593-6.

112 Canadian Task Force on the Periodic Health Examination. The periodic health examination. Can Med Assoc J 1979;121:1193-254.

113 Roddy E, Zhang W, Doherty M, Arden NK, Barlow J, Birrell F, et al. Evidence-based recommendations for the role of exercise in the management of osteoarthritis of the hip or knee - the MOVE consensus. Rheumatology (Oxford) 2005;44:67-73.

114 Moher D, Cook DJ, Eastwood S, Olkin I, Rennie D, Stroup DF. Improving the quality of reports of meta-analyses of randomised controlled trials: the QUOROM statement. Lancet 1999;354:1896-900.

115 Moher D, Schulz KF, Altman D, Lepage L. The CONSORT statement: revised recommendations for improving the quality of reports of parallel-group randomized trials. JAMA 2001;285:1987-91.

116 Hynes RB, Sacket DL, Gray JMA, Cook DJ, Guyatt GH. Transferring evidence from research into practice. 1. The role of clinical care research evidence in clinical decisions. Evidence Based Medicine 1996;1:196-7. 